AperTO - Archivio Istituzionale Open Access dell'Università di Torino

\title{
Management of older patients with multiple myeloma
}

\section{This is the author's manuscript}

Original Citation:

Availability:

This version is available http://hdl.handle.net/2318/100276

since

Terms of use:

Open Access

Anyone can freely access the full text of works made available as "Open Access". Works made available under a Creative Commons license can be used according to the terms and conditions of said license. Use of all other works requires consent of the right holder (author or publisher) if not exempted from copyright protection by the applicable law. 


\section{(3) \\ UNIVERSITÀ DEGLI STUDI DI TORINO}

This Accepted Author Manuscript (AAM) is copyrighted and published by Elsevier. It is posted here by agreement between Elsevier and the University of Turin. Changes resulting from the publishing process - such as editing, corrections, structural formatting, and other quality control mechanisms - may not be reflected in this version of the text. The definitive version of the text was subsequently published in [Blood Rev. 2011 Mar;25(2):65-73. doi: 10.1016/j.blre.2010.10.003].

You may download, copy and otherwise use the AAM for non-commercial purposes provided that your license is limited by the following restrictions:

(1) You may use this AAM for non-commercial purposes only under the terms of the CC-BY-NC-ND license.

(2) The integrity of the work and identification of the author, copyright owner, and publisher must be preserved in any copy.

(3) You must attribute this AAM in the following format: Creative Commons BY-NC-ND license (http://creativecommons.org/licenses/by-nc-nd/4.0/deed.en), [+ Digital Object Identifier link to the published journal article on Elsevier's ScienceDirect ${ }^{\circledR}$ platform $]$ 


\title{
MANAGEMENT OF OLDER PATIENTS WITH MULTIPLE MYELOMA
}

\author{
Francesca Gay, Antonio Palumbo
}

\section{ABSTRACT}

For many years, the oral combination melphalan-prednisone (MP) has been considered the standard of care for patients with multiple myeloma (MM) not eligible for autologous stem cell transplantation. In the era of novel agents, the introduction of immunomodulatory drugs and proteasome inhibitors has challenged the role of MP and lead to new standards of care for this disease. Five randomized phase III studies compared the traditional MP with the MP plus thalidomide (MPT). All these studies showed a prolonged time to progression (TTP) with the 3drug combination. However, in only two of these trials this advantage translated into an improvement in overall survival (OS). In another randomized trial, MP plus bortezomib (VMP) was correlated with an increase in both TTP and OS compared with MP. Preliminary data showed the 
superiority of the association of VMP plus thalidomide followed by bortezomib-thalidomide maintenance (VMPT-VT) vs VMP and melphalan-prednisone-lenalidomide followed by lenalidomide maintenance (MPR-R) compared to MP. Promising results have also been reported with the combination of lenalidomide plus low-dose dexamethasone. The availability of different efficacious regimens provided clinicians with the opportunity of tailoring the proper and specific approach for each patient. The choice should be based on patients' comorbidities and biologic age, while taking into account the expected toxicity profiles of each treatment regimen. Moreover, an accurate management of therapy-related adverse events and a gentler approach, particularly for patients older than 75 years, with appropriate age-adjusted dose reductions, should be considered to further improve outcome.

\section{Epidemiology}

Multiple myeloma (MM) is an incurable plasma cell disease that comprises $1 \%$ of all cancers and $10 \%$ of hematologic neoplasms. It accounts for 20,580 new cancer cases in the USA in 2009, including 11,680 cases in men, 8,900 cases in women, and 10,580 deaths overall.(1) The median age at diagnosis is 70 years, with $36 \%$ of patients younger than 65 years, $27 \%$ aged 65 to 74 years, and $37 \%$ older than 75 years. $(\mathbf{2 , 3})$ Considering the increasing life-expectancy of the normal population, the number of geriatric patients is expected to rise over time.

\section{Diagnosis and Treatment Strategy}

Recognizing organ damage and its correlation with $\mathrm{MM}$ is the very first step to correctly identify symptomatic disease and subsequently start treatment. MM is defined by the presence of monoclonal protein in the urine and/or serum, and bone-marrow plasma cells greater than $10 \%$. When no monoclonal protein is detected, an abnormal serum free light-chain ratio is a further sign of MM. 
Symptomatic disease is characterized by evidence of end-organ damage caused by plasma cell proliferation, or CRAB features: C: hypercalcemia (>11.5 mg/dL [2.65 mmol/L]); R: renal failure (serum creatinine $>2 \mathrm{mg} / \mathrm{dL}[1.73 \mathrm{mmol} / \mathrm{L}]$ ); A: anaemia (hemoglobin $<10 \mathrm{~g} / \mathrm{dL}[12.5$ $\mathrm{mmol} / \mathrm{L}]$ or $>2 \mathrm{~g} / \mathrm{dL}$ [1.25 mmol/L] below the lower limit of normal); and B: bone disease (lytic lesions, severe osteopenia or pathologic fractures).(4,5)

MM is staged according to the International Staging System (ISS). Patients may be classified in three different risk groups: Stage I, with a median survival of 62 months; patients in this group have serum $\beta 2$-microglobulin $<3.5 \mathrm{mg} / \mathrm{L}$ and serum albumin $\geq 35 \mathrm{~g} / \mathrm{L}$. Stage II, with median survival of 44 months; patients in this category have serum $\beta 2$-microglobulin $<3.5 \mathrm{mg} / \mathrm{L}$ and serum albumin $<35 \mathrm{~g} / \mathrm{L}$, or serum $\beta 2$-microglobulin $3.5-5.5 \mathrm{mg} / \mathrm{L}$. Stage III, with a median survival of 29 months; patients belonging to this stage have serum $\beta 2$-microglobulin $\geq 5.5 \mathrm{mg} / \mathrm{L}$.(6) Serum free light-chain incorporated into the ISS may improve the risk stratification.(7) Chromosomal abnormalities can be detected by using cytogenetics and fluorescent in-situ hybridization (FISH). The presence of $17 \mathrm{p}$ deletion (del 17) or $\mathrm{t}(4 ; 14)$ or $\mathrm{t}(14 ; 16)$ detected by FISH are associated with poorer outcome, hyperdiploid is associated with good outcome and $\mathrm{t}(11 ; 14)$ does not have a negative impact. Patients with isolated deletion 13 (del13) on FISH analysis do not have a worse outcome, unless this abnormality is associated with (del17) or t(4;14).(8,9) (Table 1)

Patients with symptomatic MM should be treated immediately; early intervention on asymptomatic patients showed no benefits, and observation alone is the standard.(10-12)

Treatment choice should be based on both patient's characteristics, in particular age, and scientific evidence. In many European countries, elderly patients (subjects older than 65 years) are generally considered ineligible for autologous stem cell transplantation (ASCT). However, biological age and chronological age do not always correspond, and a greater emphasis should be placed on the former rather than the latter. Beside age, other relevant factors play a fundamental role in determining whether a patient is eligible for ASCT or not, such as performance status and comorbidities. Patients are generally considered eligible for ASCT if they have normal cardiac, 
pulmonary, liver and renal functions. However, reduced dose-intensity transplantation may be a valuable option for elderly patients up to the age of 75 in good clinical conditions.

Physicians have different treatment options available for the management of MM. These treatments are defined as standard if they are supported by at least one randomized study reporting an improvement in progression-free survival (PFS); phase II studies are still considered valuable and of important scientific evidence, especially if results of phase III trials are not available.

This paper will focus on the results of the latest phase III studies on transplant ineligible patients. In the past, patients who were not candidates for ASCT were usually treated with the oral combination melphalan-prednisone (MP). The introduction of novel agents, such as immunomodulatory drugs (IMIDs) (thalidomide and lenalidomide) and proteasome inhibitors (bortezomib), has substantially changed the treatment paradigm of MM.

\section{Therapeutic Options}

\section{Melphalan and Prednisone: the old standard of care.}

For more than 40 years, the oral combination MP has been considered the standard of care for elderly patients with newly diagnosed MM, and for young patients who were not candidates for high-dose therapy. A meta-analysis of 27 randomized trials compared different chemotherapy regimens with MP: despite higher response rates reported with the different chemotherapy regimens (60.0\% vs $53.2 \%, \mathrm{P}<0.0001)$ as compared to MP, no significant difference in overall survival (OS) was detected $(\mathrm{P}=0.6)$ and MP showed to be better tolerated.(13) In a randomized trial comparing MP with melphalan plus dexamethasone (MD), high-dose dexamethasone (HD) and HD plus interferon- $\alpha$, an improvement in response rate and PFS in patients receiving melphalan as part of the induction treatment (both MP and MD) did not translate into a survival advantage; the morbidity associated with dexamethasone-containing regimens (in particular severe pyogenic infections, haemorrhage, severe diabetes, gastrointestinal and psychiatric complications) was significantly higher, and MP was generally better tolerated (14). 
Another randomized study comparing MP with thalidomide and dexamethasone (TD) showed higher response rate and longer PFS with TD. Nonetheless, patients receiving MP had a significantly longer survival, again probably due to the better tolerability of MP compared to TD: extra-hematological toxicities, mainly related to high-dose dexamethasone, were superior in patients treated with TD, leading to a higher treatment-discontinuation rate. During the first year of therapy, non-disease-related deaths in the TD group were twice as high as compared with those in the MP group, with infections being the primary cause. In patients older than 72 years with poor performance status, this difference was even more pronounced.(15) These results provided the rationale to combine the standard MP with novel agents thalidomide, bortezomib and lenalidomide.

\section{New regimens containing novel agents:}

\section{Thalidomide-based therapies}

- Thalidomide plus MP (MPT). Five randomized studies compared the combination MPT with the standard MP: partial response (PR) rate was $42 \%-76 \%$ vs $28 \%-48 \%$ with MPT and MP respectively, at least very good PR (VGPR) or near complete response (nCR) rate was $15 \%-47 \%$ vs 6\%-8\%, and PFS was 14-28 vs 10-19 months.(16-21) Although in the 2 Intergroupe Francophone du Myelome (IFM) studies, the PFS advantage observed with MPT also translated into a significant OS advantage (45-52 vs $28-32$ months), (19,20) this was not confirmed in the three other trials.(1618,21) Despite this, results obtained with MPT suggest that the three-drug combination is far superior to the traditional MP. Therefore, today MPT is considered one of the standards of care for elderly patients.

Recently a meta-analysis of pooled data of 1,682 patients from the MPT studies previously mentioned was performed. Median PFS was 20 (19-22) months in the MPT arm and 15 (14-17) months in the MP arm; median OS was 39 (35.6-39.0) months for patients who received MPT and 33 (95\% CI 30.4-36.5) months for patients treated with MP. Overall hazard ratio of MPT compared to MP was $0.67(0.55-0.80)$ for PFS and $0.82(0.66-1.02)$ for OS. This meta-analysis demonstrated a 
significant advantage for PFS and is consistent with the difference in OS observed when thalidomide is added to MP in first-line treatment to elderly patients.(22)

Grade 3-4 neutropenia mainly related to melphalan, was the main adverse event (AE) associated with MPT, ranging from $16 \%$ to $48 \%$. As for the thalidomide-related AEs, peripheral neuropathy was reported in 6\%-23\% of patients treated with MPT and venous thromboembolism (VTE) in $3 \%$ to $12 \%$ of patients.(18-21)

- $\quad$ Thalidomide plus cyclophosphamide and dexamethasone (CTD). The medical Research Council (MRC) Myeloma IX trial compared the CTD combination with the standard MP in a randomized trial including 900 patients. Higher responses were seen in patients treated with CTD as compared to MP: at least PR rate was $83 \%$ vs $46 \%$, and CR rate was $21 \%$ vs $4 \%$, respectively; however, the improvement observed with CTD did not translate into longer survival.(23)

\section{Bortezomib-based therapies}

- $\quad$ Bortezomib plus melphalan and prednisone (VMP). The combination VMP has been explored in the international VISTA (Velcade as Initial Standard Therapy) trial, which is the largest MP-based phase III study so far, evaluating a total of 682 patients. This study showed the superiority of VMP in comparison with the traditional MP for all efficacy endpoints: CR rate was $30 \%$ vs $4 \%(\mathrm{P}<0.001)$, median TTP was 24 months vs 17 months $(\mathrm{P}<0.001),(\mathbf{2 4})$ and the 3-year OS was $69 \%$ vs $54 \%,(\mathrm{P}=0.0008) .(25)$ Hematologic AEs were similar in the two groups. Grade 34 peripheral sensory neuropathy was more frequent in the VMP group (14\% vs $0 \%)$, as well as grade 3-4 gastrointestinal events (19\% vs 5\%). The rate of serious AEs in patients who received VMP was higher than in the control group ( $46 \%$ vs. $36 \%$ ), but treatment-related deaths were similar (2\% and 2\%).(24,25) Today, VMP is considered a new standard of care for myeloma patients who are not candidates for ASCT. 


\section{Bortezomib plus thalidomide based therapies}

Bortezomib plus thalidomide and prednisone (VTP). The new standard VMP has been compared to the VTP regimen in a randomized study. In both arms, bortezomib was administrated with one 6-week cycle of a twice weekly infusion (days 1, 4, 8, 11, 22, 25, 29, and 32) followed by five 5-week cycles of a weekly infusion (days 1, 8, 15 and 22). Response rates were similar: at least PR was $79 \%$ in both groups, with a CR rate of $22 \%$ vs $27 \%$, respectively in the VMP regimen and VTP regimen. After a median follow-up of 22 months, there were no significant differences in terms of 2-year TTP (VMP 75\% vs VTP 70\%), PFS (VMP 71\% vs VTP 61\%) and OS (VMP 81\% vs VTP 84\%). Grade 3-4 non hematological AEs were more frequent with VTP as compared to VMP, in particular cardiac toxicity $(8.5 \%$ vs $0 \% \mathrm{P}<0.001)$, thromboembolic events $(4 \%$ vs $<1 \%, \mathrm{P}=$ not significant $[\mathrm{NS}]$ ), and peripheral neuropathy (9\% vs $5 \%, \mathrm{P}=\mathrm{NS})$, resulting in a significantly higher rate of treatment discontinuation in the VTP arm $(17 \%$ vs $8 \%, \mathrm{P}=0.03)$. Patients who received VMP had a higher rate of neutropenia $(37 \%$ vs $21 \%, \mathrm{P}=0.003)$, thrombocytopenia $(22 \%$ vs $12 \%, \mathrm{P}$ $=0.03)$ and infections $(7 \%$ vs $<1 \%, \mathrm{P}=0.01)$. VMP proved to be better tolerated than $\mathrm{VTP}$, with no differences in survival, therefore confirmed as new standard of care for elderly myeloma patients.(26)

- $\quad$ Bortezomib plus melphalan, prednisone and thalidomide (VMPT). A recent phase III trial compared the combination VMPT followed by maintenance with VT, with VMP. Response rates were superior with the four-drug regimen: at least $\mathrm{PR}$ rate was $89 \%$ vs $81 \%(\mathrm{P}=0.01)$, at least VGPR rate was $59 \%$ vs $50 \%,(\mathrm{P}=0.03)$, and $\mathrm{CR}$ rate was $38 \%$ vs $24 \%(\mathrm{P}=0.0008)$. Increase in response rate translated into an increase in survival: after a median follow-up of 17.8 months, the 2year PFS was significantly longer in the VMPT group (70\% vs 58\%, $\mathrm{P}=0.008$ ). No differences in OS were detected between the two groups, but follow-up is still short. Grade 3-4 neutropenia was more common among VMPT patients $(38 \%$ vs $28 \%, \mathrm{P}=0.02)$, so were cardiac complications $(10 \%$ vs $5 \%, \mathrm{P}=0.04)$. The incidence of other grade $3-4$ AEs was similar in the two groups.(27) In both arms, bortezomib was initially administered with a twice-weekly schedule $\left(1.3 \mathrm{mg} / \mathrm{m}^{2}\right.$ on days 1,4 , 
8, and 11). In order to evaluate whether both regimens could be further optimized by reducing toxicity, the study protocol was amended and bortezomib administration was then reduced to a once-weekly infusion $\left(1.3 \mathrm{mg} / \mathrm{m}^{2}\right.$ on days $1,8,15$, and 22$)$. There was a significantly reduced overall incidence of grade 3-4 peripheral neuropathy $(8 \%$ versus $28 \%, \mathrm{P}<0.001)$ in the onceweekly versus twice-weekly group, without any significant change in efficacy.(28) Of note, this is the first study to show the superiority of a 4-drug combination followed by maintenance over the most recent standard therapy VMP. Moreover, this study confirmed the higher efficacy and good tolerability of the once-weekly schedule of bortezomib.

\section{Lenalidomide-based therapies}

- $\quad$ Lenalidomide and high-dose dexamethasone (RD). In a phase III randomized trial $\mathrm{RD}$ resulted in a higher $\mathrm{CR}$ rate $(21 \%)$ compared to high-dose dexamethasone alone, as well as in a significant improvement in 1-year PFS $(77 \%$ vs $55 \%, \mathrm{P}=0.02)$ and a trend towards a better OS (97\% vs $93 \%, \mathrm{P}=\mathrm{NS}$ ), but was associated with a higher incidence of grade 3-4 AEs (in particular neutropenia [14\% vs 3\%] and non-neutropenic infections [19\% vs $10 \%]$ ), that translated into an increase in treatment discontinuation.(29,30) Another open-label randomized trial compared RD with lenalidomide plus low-dose dexamethasone $(\mathrm{Rd})$ as initial therapy for newly diagnosed patients. Interestingly, in this trail the use of high-dose dexamethasone in association with lenalidomide was not associated with an increased TTP and PFS, and the 2-year OS was $87 \%$ with $\mathrm{Rd}$ and $75 \%$ with $\mathrm{RD}(\mathrm{P}<0.001)$. Treatment with high-dose dexamethasone increased the number of early deaths and the rate of AEs, in particular thromboembolic events. Considering the better toxicity profile associated with low-dose dexamethasone, all patients enrolled in the RD group crossed over to Rd treatment. The landmark analysis at 4 months showed the impact of different treatment approaches: 3-year OS for patients who continued on primary therapy beyond 4 months was $79 \%$, whereas it was only $55 \%$ in patients who stopped treatment after 4 months.(31) A subsequent subgroup analysis confirmed the good tolerability and the efficacy of Rd in the subset of 
patients older than 70 years.(32) Considering the good tolerability and the efficacy of this regimen, Rd continued until progression can be considered a valuable option for patients older than 65 years.

- $\quad$ Lenalidomide plus melphalan and prednisone (MPR). The European Myeloma Network phase III study compared MPR with standard MP. Patients were randomly assigned to receive MPR followed by lenalidomide maintenance therapy (MPR-R), or MPR followed by placebo maintenance, or MP followed by placebo maintenance. Responses were significantly higher with MPR-R: at least PR rate was $77 \%$ in the MPR-R arm, with at least VGPR in $32 \%$ of patients and $\mathrm{CR}$ in $16 \%$, while the corresponding figures with MP were $50 \%, 12 \%$, and $4 \%(\mathrm{P}<0.001)$. Similarly, 2-year PFS was considerably improved in patients who received MPR-R compared with those who received MP followed by placebo maintenance (55\% vs 16\%, P < 0.001). No differences were noted in the 1-year OS (92\% in both arms). Grade 3-4 hematologic AEs were more frequent with MPR-R than with MP (neutropenia $71 \%$ vs $30 \%$, and thrombocytopenia $38 \%$ vs $14 \%$ ). The more common grade 3-4 non hematologic AEs were infections (10\% of patients receiving MPR-R vs $8 \%$ of those receiving MP), and fatigue (5\% vs $3 \%$ with MPR-R and MP, respectively). None patients in both groups experienced a grade 3-4 peripheral neuropathy.(33) These data suggest that MPR-R may be considered a new and valuable standard of care for patients older than 65 years or for younger patients not eligible for ASCT.

The efficacy of the treatments described above have been summarized in Table 2. The most frequent grade 3-4 AEs associated with these regimens have been summarized in Table 3.

\section{Autologous transplant in elderly patients}

Patients older than 65 years, as well as those with significant comorbidities, are generally not considered candidates for standard melphalan $200 \mathrm{mg} / \mathrm{m}^{2}$ followed by ASCT. A randomized trial exploring the efficacy of high-dose chemotherapy and transplant in patients with newly diagnosed MM showed a significantly higher 5-year OS in patients younger than 65 years undergoing ASCT compared to elderly subjects (68\% vs $50 \%$, respectively; $\mathrm{P}=0.008) .(34)$ Two randomized studies 
compared intermediate dose melphalan (Melphalan $100 \mathrm{mg} / \mathrm{m}^{2}$ - Mel 100) and reduced-intensity ASCT with standard MP. The first study included patients aged 65 to 70 years, and showed that reduced-intensity ASCT leads to better event-free survival (EFS) and OS as compared to standard MP.(37) The second study included patients aged 65 to 75 years, and compared reduced-intensity ASCT with both standard MP and with MPT: in this trial, PFS and OS were longer in patients treated with MPT compared with MP or Mel100, and no differences between MP and Mel100 were found.(20) A recent phase II trial evaluated the safety and efficacy of novel agents incorporated in both pre-transplant induction and post-transplant consolidation and maintenance, in patients aged 65-75 years, who received reduced intensity ASCT (Mel100): the CR rate was 13\% after induction with bortezomib, $43 \%$ after Mel100, and 73\% during consolidation-maintenance with lenalidomide. During bortezomib induction, grade 3-4 toxicities included thrombocytopenia (17\%), neutropenia (10\%), peripheral neuropathy (16\%) and pneumonia (10\%). Lenalidomide consolidationmaintenance was well tolerated, with no cumulative or persistent grade 3-4 neutropenia (16\%) and/or thrombocytopenia (6\%); pneumonia (5\%) and cutaneous rash (4\%) were the more frequent extra-hematologic AEs.(38) Data from these trials suggest that the reduced-intensity ASCT is a valuable approach for both elderly patients and younger subjects with pre-existing comorbidities, for whom full-dose chemotherapy and ASCT may be too toxic. A sequential approach, including bortezomib as induction, reduced intensity ASCT and lenalidomide as consolidation-maintenance lead to a progressive improvement in response rates, by taking advantage of a subsequent exposure to different drugs.

\section{Role of maintenance therapy in elderly patients}

Only few studies on the role of maintenance therapy in elderly patients are available.

Maintenance with VT has been tested in the Italian study comparing VMPT-VT vs VMP. An exploratory analysis performed on the 82 VMPT-VT patients who received at least 6 months of VT maintenance showed an improvement in CR rate from 58\% after 9 cycles of VMPT to $62 \%$ after 6 
months of VT maintenance.(27) Mateos and colleagues investigated the role of maintenance therapy with bortezomib plus prednisone (VP) vs bortezomib plus thalidomide (VT) in elderly patients respectively assigned to induction with VMP and VTP. An overall improvement in the CR rate was detected with maintenance treatment (from $25 \%$ up to $42 \%$ ), and no significant differences in response rates between the two arms were seen (38\% and 46\%, respectively with VP and VT). After a median duration of maintenance of 13 months, there was a trend towards a lower TTP with VP compared with VT (1-year TTP:71\% vs 84\%; P=0.05), though no significant difference was found in terms of OS (89\% vs 92\%, respectively with VP and VT). (26).

In the European Myeloma Network phase III study, after induction with MPR, patients were randomized to receive lenalidomide or placebo maintenance until progression: landmark analysis showed that the addition of lenalidomide maintenance to MPR decreased the risk of progression by $69 \%$. The survival advantage was also confirmed in the very elderly patient population older than 75 years.(33) This is an unprecedented result, and it supports the positive role of maintenance with lenalidomide.

\section{Management of AEs}

Management of AEs plays a key role in optimizing the efficacy of treatment, especially in elderly patients. The studies described above showed that the toxicity associated to a regimen may jeopardize the efficacy of the treatment itself, and consequently may negatively affect survival rates. Indeed, despite the better results achieved with TD compared to MP, TD is more toxic, and this represents a essential limitation of that combination.(15) The efficacy of the treatments previously described should therefore be balanced against the toxicity. The National Cancer Institute Common Terminology Criteria (NCI-CTC) should be used to uniformly grade AEs.(35) On the basis of the seriousness of the event, physicians should take proper action. Generally, at the occurrence of any grade 4 or higher hematological or grade 3 or higher non-hematologic toxicities, treatment should be immediately withheld until the toxicity resolves to grade 1. Upfront reduction of the drug-doses 
according to patients' age must be considered, since older patients are likely to benefit more from a gentler approach (Table 4). Here, we report a description of the main AEs related to MM and linked to the use of novel agents, providing an overview of the possible specific interventions to manage AEs.

\section{Hematologic toxicities}

\section{Neutropenia}

Neutropenia is quite frequent in MM patients treated with new drugs in combination with alkylating agents, but less frequent when they are used with dexamethasone alone.Using granulocyte-colony stimulating factor (G-CSF) is an efficacious and well tolerated method to decrease or prevent neutropenia. When neutropenia reaches grade 4 (neutrophilic count $<500 / \mathrm{mm}^{3}$ ) despite G-CSF, treatment should be suspended. Treatment can be restarted when the AE resolves to grade 2 (neutrophilic count $\geq 1000 / \mathrm{mm}^{3}$ ), but appropriate dose reduction are necessary. The greatest concern linked to neutropenia is the risk of infections. Prophylaxis with G-CSF is recommended to prevent febrile neutropenia in patients at high-risk on the basis of age, medical history, disease characteristics, and the expected myelotoxicity of the chemotherapy regimen. (36)

\section{Thrombocytopenia}

The use of bortezomib, lenalidomide, alkylating agents and their combinations are commonly associated with this AE, while treatment with thalidomide alone or plus steroids rarely causes thrombocytopenia. When thrombocytopenia reaches grade 4 (platelet count $<25,000 / \mathrm{mm}^{3}$ ), treatment should be interrupted; it can then be restarted when the event resolves to grade 2 (platelet count $<50,000 / \mathrm{mm}^{3}$ ), with appropriate dose-reduction of the suspected drug. (36)

\section{Anemia}


Anemia is generally related to $\mathrm{MM}$, especially in case of recurrent or refractory disease.(37) In order to prevent functional iron or vitamin deficiency and to support increased erythropoiesis, a prompt monitoring of the iron and vitamin status is necessary. Erythropoiesis-stimulating agents (ESAs) are recommended to manage treatment-related anemia, generally when the haemoglobin concentration is less than $10 \mathrm{~g} / \mathrm{dL}$ and no improve despite response to therapy has been shown; however, treatment can begin earlier at physicians' discretion (haemoglobin 10 to $12 \mathrm{~g} / \mathrm{dL}$ ) for patients with heart disease or those who have difficulties undertaking regular daily activities. The dose of ESAs should be adjusted to keep the hemoglobin concentration around 11 to $12 \mathrm{~g} / \mathrm{dL}$, to avoid blood transfusion and anemia-related symptoms. In case the hemoglobin concentration is greater than $12 \mathrm{~g} / \mathrm{dL}$, serious heart problems may occur and the risk of thrombosis should be taken into account.(38)

\section{Extra-hematologic toxicities}

\section{Infections}

The disease itself can cause impairment in immune function, with consequent increase in risk of infections. The risk is therefore higher in case of active disease but decreases when the patient responds to therapy. Treatment, and in particular the use of high-dose dexamethasone and myelotoxic drugs that can cause neutropenia, increases the risk of infections. Herpes zoster is a possible complication related to bortezomib administration.(39)

For patients receiving high-dose dexamethasone, elderly patients, patients with comorbidities that increase the risk of infections (i.e. chronic obstructive pulmonary disease, diabetes, renal function impairment), and for patients with an increased infection rate, routine oral antibiotic prophylaxis could be considered at least for the first 3 months of therapy. Trimethoprimsulphamethoxazole should be used at least during the first 2-3 months of chemotherapy or during steroid administration.(39) For all patients receiving treatment with bortezomib, acyclovir prophylaxis demonstrated effective in decreasing the incidence of zoster reactivation.(24) 


\section{Peripheral neuropathy}

Treatments with bortezomib and thalidomide can cause peripheral neuropathy. Incidence of grade 3-4 neuropathy is similar in thalidomide- or bortezomib-based regimens, in both relapsed and newly diagnosed settings. Both thalidomide and bortezomib-related neuropathies are cumulative and linked to the dose administered. While bortezomib interruption relieves neuropathic symptoms (40), discontinuation of thalidomide generally does not improve the treatment-related neuropathy.(41) By contrast, grade 3-4 peripheral neuropathy rarely occurs in patients treated with lenalidomide, and lenalidomide has been administered to patients who have received prior thalidomide treatment without further deterioration of preexisting thalidomide-related neuropathy. $(\mathbf{4 2 , 4 3 )}$

To date, there are no pharmacological drugs able to effectively relieve neuropathic symptoms, and modifying promptly the schedule of the drug or reducing the dose is the most effective measure to treat this condition. Patients should be instructed on how to recognize peripheral neuropathy, and to promptly search for medical care. For bortezomib-treated patients, in case of grade 1 with pain or grade 2 peripheral neuropathy, a dose reduction of bortezomib to 1.0 $\mathrm{mg} / \mathrm{m}^{2}$ is recommended; for grade 2 with pain or grade 3 peripheral neuropathy interruption of bortezomib is recommended until peripheral neuropathy resolves, and then it can be restarted at 0.7 $\mathrm{mg} / \mathrm{m}^{2}$; when peripheral neuropathy reaches grade 4 , prompt interruption of bortezomib is highly recommended.(44) The recent phase 3 study comparing VMPT-VT vs VMP suggests that reducing bortezomib schedule from a twice-weekly infusion (starting dose $1.3 \mathrm{mg} / \mathrm{m}^{2}$ twice a week for a total of 4 doses every treatment cycle) to a once-weekly infusion (same dose $1.3 \mathrm{mg} / \mathrm{m}^{2}$ once weekly for a total of 4 doses every treatment cycle) is an optimal alternative. Subsequent dose reductions are $1.0 \mathrm{mg} / \mathrm{m}^{2}$ once weekly and, if necessary, $0.7 \mathrm{mg} / \mathrm{m}^{2}$ per week can be the following steps.(28)

For patients treated with thalidomide, in case of grade 1 sensory neuropathy, the assigned dose should not be modified, while, if it reaches grade 2 , thalidomide dose should be reduced by 
$50 \%$; if neuropathy reaches grade 3 , discontinuation is necessary. Thalidomide can then be resumed at a lower dose when the event improves to grade 1.(41)

\section{Thrombosis}

The incidence of VTE in MM patients ranges from $3 \%$ to $10 \%$, and is particularly related to the type of drug used to treat the patient. Bortezomib was never found to be linked to an increased risk of VTE, nor were thalidomide or lenalidomide alone. Conversely, the risk of VTE considerably increases when dexamethasone or chemotherapy are added to IMIDs, particularly in newly diagnosed patients, while the risk of VTE at relapse is lower, especially in thalidomide-treated patients.(45)

So far, there are no data on which is the best thromboprophylaxis to use in MM patients treated with IMIDs. The Italian Myeloma Network GIMEMA designed a phase III study to address this question and to compare the efficacy and safety of low-molecular-weight heparin (LMWH), low-fixed-dose warfarin $(1.25 \mathrm{mg} /$ day $)$, or low-dose aspirin as VTE prophylaxis in newly diagnosed patients, who received primary induction with thalidomide-based regimens. Preliminary results showed that serious VTE episodes were equally reported in the ASA and LMWH groups (3.6\% of patients vs $2.7 \%$ of patients, respectively, $\mathrm{P}=0.17$ ), while the incidence of VTE was significantly higher in patients receiving warfarin prophylaxis compared to LMWH patients $(6.4 \%$ of patients vs $2.7 \%$ of patients, respectively, $\mathrm{P}=0.02)$.(46) These results are consistent with the VTE incidence detected in another phase III trial comparing ASA with LMWH, where newly diagnosed patients were treated with Rd induction (VTE rate $2 \%$ vs $1 \%$ respectively, $\mathrm{P}=\mathrm{NS}) .(\mathbf{4 7})$

Baseline coagulation tests and screening for VTE are not required in asymptomatic patients. Presence of risk factors for thrombosis in MM patients treated with IMIDs should be evaluated in order to choose the best antithrombotic prophylaxis. The risk factors to determine whether a patient should be considered at high risk of thromboembolism can be classified as follows: individual risk factors that include previous history of VTE, inherited thrombophilia, age, obesity, comorbidities 
such as cardiac disease, chronic renal disease, diabetes, infections, immobilization, presence of central venous catheter and surgical procedures; myeloma-related risk factors including diagnosis and hyperviscosity; therapy-related risk factors, that is to say high-dose dexamethasone, doxorubicin, or multiagent chemotherapies, or immunomodulatory compounds. Patients with therapy-related risk factors should be considered per se to be at high-risk. If none or one individual or myeloma-related risk factor is present, aspirin ( $81-325 \mathrm{mg} /$ day $)$ is the most appropriate prophylaxis. If two or more individual or myeloma-related or therapy-related risk factors are detected, LMWH (equivalent of enoxaparin $40 \mathrm{mg} /$ day) or full-dose warfarin (international normalized ratio [INR] target 2-3) should be used. Prophylaxis is generally recommended for at least the first 4-6 months. Patients who experienced VTE during treatment can either continue the treatment or suspend it and then start it again after improvement/resolution. Patients who experienced VTE despite taking aspirin should receive LMWH; patients treated with prophylactic LMWH should switch to therapeutic doses.(45)

\section{Renal failure}

Factors involved in the pathogenesis of renal failure include the capacity of the light-chain component of the immunoglobulin to cause proximal tubular damage, dehydration, hypercalcemia, hyperuricemia, infections, and use of nephrotoxic drugs. Appropriate hydration, urine alkalinization, treatment of hypercalcemia, hyperuricemia and infections, and active therapy with rapid decrease of the proteinuria prevent further deterioration of the renal function.(48) In case of renal failure, no dose modifications of thalidomide and bortezomib are needed. Lenalidomide dose reductions are instead mandatory depending on the creatinine clearance values: between 30 and 60 $\mathrm{mL} / \mathrm{min}$, the recommended dose of lenalidomide is $10 \mathrm{mg}$ per day; with a value lower than 30 $\mathrm{mL} / \mathrm{min}$, the recommended dose is $15 \mathrm{mg}$ every other day for patients not requiring dialysis; if creatinine clearance is inferior to $30 \mathrm{~mL} / \mathrm{min}$ and the patient requires dialysis, lenalidomide dose is 
$5 \mathrm{mg}$ per day after dialysis on dialysis days. In patients receiving lenalidomide-containing therapies, a constant monitoring of the hematologic function is necessary, particularly in the early cycles.(49)

\section{Bone disease}

Skeletal complications, such as vertebral compression or collapse from osteoporosis, and pain arising from these complications, are common in MM patients. Systemic analgesia, local measures (like radiotherapy), and obviously chemotherapy, acting against the disease itself, are all important to relieve the pain.(50)

For what concerns local measures, radiotherapy is effective for bone pain relief.(51,52) Vertebroplasty is another effective method against local pain. It strengthens the bone, but still does not restore vertebral height.(53) A recent randomized phase III study of balloon kyphoplasty detected a considerable reduction in back pain and disability at one month after procedure.(54) Different types of analgesia are available to relieve bone pain, such as simple non-opioid analgesics, particularly indicated in case of mild to moderate pain. Weak opioids should be used when non opioid analgesic are inefficacious, but a particular caution should be paid to their administration, since they may cause confusion, drowsiness, and eventually constipation. In case of moderate to severe pain, strong natural opioids or also synthetic opioids can be administered.(55)

Bisphosphonate are recommended to prevent new bone lesions and skeletal events.(56) Recently, a survival benefit has been reported in newly diagnosed patients receiving zolendronic acid.(57) Given the potential risk of osteonecrosis of the jaw, a comprehensive dental examination and appropriate preventive dentistry is required.(58)

\section{Gastrointestinal AEs}

Gastrointestinal side effects are rarely related to myeloma but they are commonly linked to therapy. Thalidomide treatment may usually lead to constipation, while the use of lenalidomide 
most frequently causes diarrhea. Both constipation and diarrhea have been reported with bortezomib-based regimens.

Patients suffering from diarrhea should maintain a high fluid intake; antidiarrheal drugs can be used, after exclusion of active infections. In case of grade 3-4 toxicity, a 50\% dose reduction of the suspected drug is recommended. Patients should maintain a high fluid intake in case of constipation as well. An additional help may be a high fiber diet, if medically appropriate. When necessary, stool softeners and osmotic laxatives can be administered.

\section{Dermatologic AEs}

The use of both thalidomide and lenalidomide is often associated with dermatologic toxicity, most frequently rash, dry skin and mouth and atrophic lesions. These side effects are usually mild to moderate and they can be easily managed. Toxic epidermic necrolysis and StevensJohnson syndrome are more serious, but fortunately quite uncommon.(41) Bortezomib-based treatments only rarely can cause dermatologic side effects: the highest rate was reported with the association of bortezomib and pegylated-liposomal-doxorubicin in relapsed patients, where the main AE was hand-foot syndrome related to pegylated-liposomal-doxorubicin.(59,60)

Physicians should be very cautious while co-administering thalidomide or lenalidomide with agents with known dermatologic toxicity, such as sulfonamides, allopurinol, cotrimoxazole. In these cases a careful monitoring is needed. When mild toxicities occur, temporary discontinuation is generally the best method to solve the rash. If necessary, treatment should begin with antihistamines; if rash persists, low-dose prednisone (10-20 mg/day for up to 14 days) should be added. In case of severe toxicity, the treatment should be interrupted until complete resolution and with $50 \%$ dose reductions. After toxic epidemic necrolysis or the Stevens-Johnson syndrome, readministration of the responsible drug is contraindicated.

\section{Conclusion}


The combination of conventional chemotherapy or low-dose dexamethasone with new drugs has substantially changed the treatment paradigm for patients with MM, increasing therapeutic options available for this disease. Randomized phase III studies have shown that MPT, MPV and MPR-R proved to be more effective than the traditional treatment with MP; hence, they can now be regarded as new standards of care for patients ineligible for ASCT. The four-drug combination VMPT followed by VT maintenance recently showed to be a more effective regimen than VMP, and represents another valuable option for elderly MM patients. Preliminary results on Rd are also encouraging, but they still need to be further supported and confirmed in comparative studies with three- and four- drug combinations.

Physicians have now a wider variety of treatment options available. They can tailor more personalized therapies according to the patients' characteristics and comorbidities, by balancing efficacy and toxicity of the treatment regimens. This improves both the quality of life and outcome, and subsequently represents a great advantage for the patient. 


\section{REFERENCES:}

1. Jemal A, Siegel R, Ward E, Hao Y, Xu J, Thun MJ. Cancer statistics. CA Cancer J Clin. $2009 ; 59,225-49$.

2. Ferlay J, Bray F, Pisani P, et al. GLOBOCAN 2002 Cancer Incidence, Mortality and Prevalence Worldwide. IARC CancerBase No. 5 Version 2.0. Lyon: IARC Press; 2004.

3. Horner MJ, Ries LAG, Krapcho M, et al. SEER Cancer Statistics Review, 1975-2006, National Cancer Institute http://seer.cancer.gov/statfacts/html/mulmy.html. Accessed on 30 March 2010.

4. Durie BG, Kyle RA, Belch A, et al. Myeloma management guidelines: a consensus report from the Scientific Advisors of the International Myeloma Foundation. Hematol J. 2003;4:379-98.

5. Kyle RA, Rajkumar SV. Criteria for diagnosis, staging, risk stratification and response assessment of multiple myeloma. Leukemia. 2009;23:3-9.

6. Greipp PR, San Miguel J, Durie BG, et al. International staging system for multiple myeloma. J Clin Oncol. 2005;23:3412-3420.

7. Snozek CL, Katzmann JA, Kyle RA, et al. Prognostic value of the serum free light chain ratio in newly diagnosed myeloma: proposed incorporation into the international staging system. Leukemia. 2008;22:1933-1937. 
8. Fonseca R, Barlogie B, Bataille R, et al. Genetics and cytogenetics of multiple myeloma: a workshop report. Cancer Res. 2004;64:1546-1558.

9. Dewald GW, Therneau T, Larson D, et al. Relationship of patient survival and chromosome anomalies detected in metaphase and/or interphase cells at diagnosis in myeloma. Blood. 2005;106:3553-3558.

10. Kyle RA, Remstein ED, Therneau TM, et al. Clinical course and prognosis of smoldering (asymptomatic) multiple myeloma. N Engl J Med 2007; 356:2582-90.

11. He Y, Wheatley K, Clark O, Glasmacher A, Ross H, Djulbegovic B. Early versus deferred treatment for early stage multiple myeloma. Cochrane Database Syst Rev. 2003.

12. Kyle RA, Durie BGM, Rajkumar SV, et al. Monoclonal gammophaty of undetermined significance (MGUS) and smoldering (asymptomatic) multiple myeloma. IMWG consensus perspectives risk factors for progression and guidelines for monitoring and management. Leukemia 2010; 24:1121-1127.

13. Myeloma trialists' Collaborative Group. Combination chemotherapy versus melphalan plus prednisone as treatment for multiple myeloma: an overview of 6,633 patients from 27 randomized trials. J Clin Oncol 1998; 16,3832-3842

14. Facon T, Mary JY, Pégourie B, et al. Dexamethasone-based regimens versus melphalanprednisone for elderly multiple myeloma patients ineligible for high-dose therapy. Blood. 2006; 107, 1292-1298.

15. Ludwig H, Hajek R, Tóthová E, et al. Thalidomide-dexamethasone compared with melphalan-prednisone in elderly patients with multiple myeloma. Blood. 2009; 113, 34353442.

16. Guldbrandsen N, Waage A, Gimsin P, et al. A randomised placebo controlled study with melphalan/prednisone vs melphalan/prednisone/thalidomide: quality of life and toxicity [abstract]. Haematologica. 2008; 93, abstract 0209. 
17. Palumbo A, Bringhen S, Caravita T, et al. Oral melphalan and prednisone chemotherapy plus thalidomide compared with melphalan and prednisone alone in elderly patients with multiple myeloma: randomised controlled trial. Lancet. 2006; 367, 825-831.

18. Palumbo A, Bringhen S, Liberati AM, et al. Oral Melphalan, prednisone and thalidomide in elderly patients with multiple myeloma: updated results of a randomized controlled trial. Blood. 2008; 112, 3107-3114.

19. Facon T, Mary JY, Hulin C, et al. Melphalan and prednisone plus thalidomide versus melphalan and prednisone alone or reduced-intensity autologous stem cell transplantation in elderly patients with multiple myeloma (IFM 99-06): a randomized trial. Lancet. 2007; 370, $1209-1218$

20. Hulin C, Facon T, Rodon P, et al. Efficacy of melphalan and prednisone plus thalidomide in patients older than 75 years with newly diagnosed multiple myeloma: IFM 01/01 trial. J Clin Oncol. 2009; 27, 3664-3670.

21. Wijermans P, Schaafsma M, Termorshuizen F, et al. Phase III study of the value of thalidomide added to melphalan plus prednisone in elderly patients with newly diagnosed multiple myeloma: the HOVON 49 Study. J Clin Oncol 2010;28:3160-6.

22. Waage A, Palumbo A, Fayers P, et al. MP versus MPT for previously untreated elderly patients with multiple myeloma: A meta-analysis of 1,682 individual patient data from six randomized clinical trials [abstract]. J Clin Oncol. 2010; 28(7s), abstract 8130.

23. Morgan GJ, Faith ED, Walter MG, et al. The addition of Thalidomide to the Induction Treatment of Newly Presenting Myeloma Patients Increases the CR Rate Which Is Likely to Translate Into Improved PFS and OS [abstract]. Blood. 2009; 114, abstract 352.

24. San Miguel JF, Schlag R, Khuageva NK, et al. Bortezomib plus melphalan and prednisone for initial treatment of multiple myeloma. N Engl J Med. 2008; 359, 906-917.

25. Mateos MV, Richardson PG, Schlag R, et al. Bortezomib plus melphalan and prednisone compared with melphalan and prednisone in previously untreated multiple myeloma: 
updated follow-up and impact of subsequent therapy in the phase III VISTA trial. J Clin Oncol. 2010; 28, 2259-66.

26. Mateos MV, Oriol A, Martinez J, et al. A Prospective, Multicenter, Randomized, Trial of Bortezomib/Melphalan/Prednisone (VMP) Versus Bortezomib/Thalidomide/Prednisone (VTP) as Induction Therapy Followed by Maintenance Treatment with Bortezomib/Thalidomide (VT) Versus Bortezomib/Prednisone (VP) in Elderly Untreated Patients with Multiple Myeloma Older Than 65 Years [abstract]. Blood. 2009; 114: abstract 3.

27. Palumbo A, Bringhen S, Rossi D, et al. Bortezomib-Melphalan-Prednisone-Thalidomide Followed by Maintenance with Bortezomib-Thalidomide for Initial Treatment of Multiple Myeloma: a Randomised Controlled Trial. J Clin Oncol. In press

28. Bringhen S, Larocca A, Rossi D, et al. Efficacy and safety of once weekly bortezomib in multiple myeloma patients. Blood 2010. In press.

29. Zonder JA, Crowley J, Hussein MA, et al. Superiority of Lenalidomide (Len) Plus Highdose Dexamethasone (HD) Compared to HD Alone as Treatment of Newly-Diagnosed Multiple Myeloma (NDMM): Results of the Randomized, Double-Blinded, PlaceboControlled SWOG Trial S0232 [abstract]. Blood. 2007; abstract 77

30. Zonder JA, Crowley J, Bolejack V, et al. A randomized Southwest Oncology Group study comparing dexamethasone (D) to lenalidomide + dexamethasone (LD) as treatment of newly-diagnosed multiple myeloma (NDMM): Impact of cytogenetic abnormalities on efficacy of LD, and updated overall study results [abstract]. J Clin Oncol. 2008; abstract 8521.

31. Rajkumar SV, Jacobus S, Callander NS, et al. Lenalidomide plus high-dose dexamethasone versus lenalidomide plus low-dose dexamethasone as initial therapy for newly diagnosed multiple myeloma: an open-label randomised controlled trial. Lancet Oncol. 2010;11(1):2937. 
32. Jacobus S, Callander N, Siegel D, et al. Outcome Of Elderly Patients 70 Years And Older With Newly Diagnosed Myeloma In The ECOG Randomized Trial Of Lenalidomide/HighDose Dexamethasone (RD) Versus Lenalidomide/Low-Dose Dexamethasone (Rd) [abstract]. Haematol. 2010; 95:149 [Abstract 370]

33. Palumbo A, Dimopoulos M, Delforge M, et al. A Phase 3 Study To Determine The Efficacy And Safety Of Lenalidomide Combined With Melphalan And Prednisone In Patients $=65$ Years With Newly Diagnosed Multiple Myeloma (NDMM) [abstract]. Haemtaol. 2010; 95, 234, abstract 566 .

34. Barlogie B, Tricot G, Anaisse MD, et al. Thalidomide and Hematopoietic-Cell Transplantation for Multiple Myeloma. N Enlg J Med. 2006; 354,1021-1030.

35. National Cancer Institute. Common Terminology Criteria for Adverse Events, v3.0, $\begin{array}{lllll}\text { (CTCAE) retrievable the link } & \text { at }\end{array}$ http://ctep.cancer.gov/protocolDevelopment/electronic_applications/ctc.htm\#ctc_v30

36. Palumbo A, Gay F. How to treat elderly patients with multiple myeloma: combination of therapy or sequencing. Hematology Am Soc Hematol Educ Program. 2009;566-77.

37. Birgegård G, Gascón P, Ludwig H. Evaluation of anaemia in patients with multiple myeloma and lymphoma: findings of the European CANCER ANAEMIA SURVEY. Eur J Haematol. 2006;77:378-86.

38. Rizzo JD, Somerfield MR, Hagerty KL, et al. Use of epoetin and darbepoetin in patients with cancer: 2007 American Society of Clinical Oncology/American Society of Hematology clinical practice guideline update. J Clin Oncol 2008;26:132-49.

39. Nucci M, Anaissie E. Infections in patients with multiple myeloma in the era of high-dose therapy and novel agents. Clin Infect Dis 2009;49:1211-25.

40. Argyriou A, Iconomou G, Kalofonos HP. Bortezomib-induced peripheral neuropathy in multiple myeloma: a comprehensive review of the literature. Blood. 2008; 112, 1593-1599. 
41. Palumbo A, Facon T, Sonneveld P, et al. Thalidomide for treatment of multiple myeloma: 10 years later. Blood. 2008; 111, 3968-3977.

42. Weber DM, Chen C, Niesvizky R, et al. Lenalidomide plus dexamethasone for relapsed multiple myeloma in North America. N Engl J Med. 2007; 357, 2133-2142.

43. Dimopoulos M, Spencer A, Attal M, et al. Lenalidomide plus dexamethasone for relapsed or refractory multiple myeloma. N Engl J Med. 2007; 357, 2123-2132

44. Richardson PG, Sonneveld P, Schuster MW, et al. Reversibility of symptomatic peripheral neuropathy with bortezomib in the phase III APEX trial in relapsed multiple myeloma: impact of a dose-modification guideline. Br J Haematol 2009;144:895-903.

45. Palumbo A, Rajkumar SV, Dimopoulos MA, et al. Prevention of thalidomide- and lenalidomide-associated thrombosis in myeloma. Leukemia. 2008; 22, 414-423.

46. Palumbo A, Cavo M, Bringhen S, et al. A Phase III Study of Enoxaparin vs Aspirin vs Low-Dose Warfarin as Thromboprophylaxis for Newly Diagnosed Myeloma Patients Treated with Thalidomide Based-Regimens [abstract]. Blood. 2009; 114: abstract 492.

47. Palumbo A, Cavallo F, Ben Yehuda D, et al. A Prospective, Randomized Study of Melphalan, Prednisone, Lenalidomide (MPR) versus Melphalan (200 Mg/M2) and Autologous Transplantation (Mel200) in Newly Diagnosed Myeloma Patients: An Interim Analysis. Blood. (ASH Annual Meeting Abstracts).2009;114:350.

48. Dimopoulos MA, Kastritis E, Rosinol L, Bladé J, Ludwig H. Pathogenesis and treatment of renal failure in multiple myeloma. Leukemia. 2008;22:1485-93.

49. Ltd C, inventor Revlimid® (lenalidomide) Product Information. Celgene Europe Limited. Berkshire, SL4 1NA UK. March 2009. Available from URL: http://emc.medicines.org.uk/printfriendlydocument.aspx?documentid=19841\&companyid=1 8682009. 
50. Dimopoulos M, Terpos E, Comenzo RL, et al. International myeloma working group consensus statement and guidelines regarding the current role of imaging techniques in the diagnosis and monitoring of multiple Myeloma. Leukemia 2009;23:1545-56.

51. Mill WB, Griffith R. The role of radiation therapy in the management of plasma cell tumours. Cancer 1980; 45, 647-652.

52. Leigh BR, Kurtts TA, Mack CF, et al. Radiation therapy for the palliation of multiple myeloma. Int J Radiat Oncol Biol Phys. 1993; 25, 801-804.

53. Hussein MA, Vrionis FD, Allison R, et al. The role of vertebral augmentation in multiple myeloma: International Myeloma Working Group Consensus Statement. Leukemia 2008; $22,1479-1484$.

54. Berenson JR, Tillman JB, Hussein MA, et al. A phase III trial of kyphoplasty versus nonsurgical care for cancer patients with vertebral fractures [abstract]. Clin Lymphoma Myeloma. 2009; 28, abstract 204.

55. Cancer pain relief and palliative care. Report of a WHO Expert Committee. World Health Organization Technical Report Series 1990;804:1-75

56. Terpos E, Sezer O, Croucher PI, et al. The use of bisphosphonates in multiple myeloma: recommendations of an expert panel on behalf of the European Myeloma Network. Ann Oncol. 2009;20:1303-17.

57. Morgan G, Davies F,Gregory W, et al. Zoledronic acid (Zol) prolongs time to first skeletalrelated event (SRE) and survival versus clodronate in newly diagnosed multiple myeloma (MM): Mrc Myeloma IX Trial Results. Zoledronic acid (Zol) significantly increases progression-free survival (PFS) versus Clodronate and may improve response rates in newly diagnosed multiple myeloma (MM): Mrc Myeloma IX Trial Results. Haematologica 2010;95:0562.Abstract. 
58. Dickinson M, Prince HM, Kirsa S, et al. Osteonecrosis of the jaw complicating bisphosphonate treatment for bone disease in multiple myeloma: an overview with recommendations for prevention and treatment. Intern Med J 2009;39:304-16.

59. Richardson PG, Sonneveld P, Schuster MW, et al. Bortezomib or high-dose dexamethasone for relapsed multiple myeloma. N Engl J Med. 2005; 352, 2487-2498.

60. Orlowski RZ, Nagler A, Sonneveld P, et al. Randomized Phase III study of Pegylated Liposomal Doxorubicin Plus Bortezomib Compared With Bortezomib Alone in Relapsed or Refractory Multiple Myeloma: Combination Therapy Improves Time to Progression. J Clin Oncol. 2007; 25, 3892-3901.

Table 1. Diagnostic criteria, baseline evaluation and staging system

\begin{tabular}{|c|c|}
\hline & $\begin{array}{c}\text { At least } 10 \% \text { clonal bone marrow plasma cells plus serum and/or urinary monoclonal protein } \\
\text { plus }\end{array}$ \\
Myeloma-related organ dysfunction, CRAB criteria: \\
$-\mathrm{C}:$ hypercalcemia (serum calcium $>11.5 \mathrm{mg} / \mathrm{dl},[2.65 \mathrm{mmol} / \mathrm{l}])$ \\
$-\mathrm{R}:$ renal insufficiency (serum creatinine $>2 \mathrm{mg} / \mathrm{dl},[1.73 \mathrm{mmol} / \mathrm{l}])$ \\
$-\mathrm{A}:$ anemia (hemoglobin $<10 \mathrm{~g} / \mathrm{dl},[12.5 \mathrm{mmol} / \mathrm{l}] \mathrm{or}>2 \mathrm{~g} / \mathrm{dl}[1.25 \mathrm{mmol} / \mathrm{l}]$ below the lower \\
limit of normal)
\end{tabular}




\begin{tabular}{|c|c|}
\hline 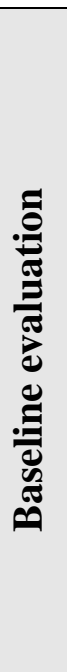 & 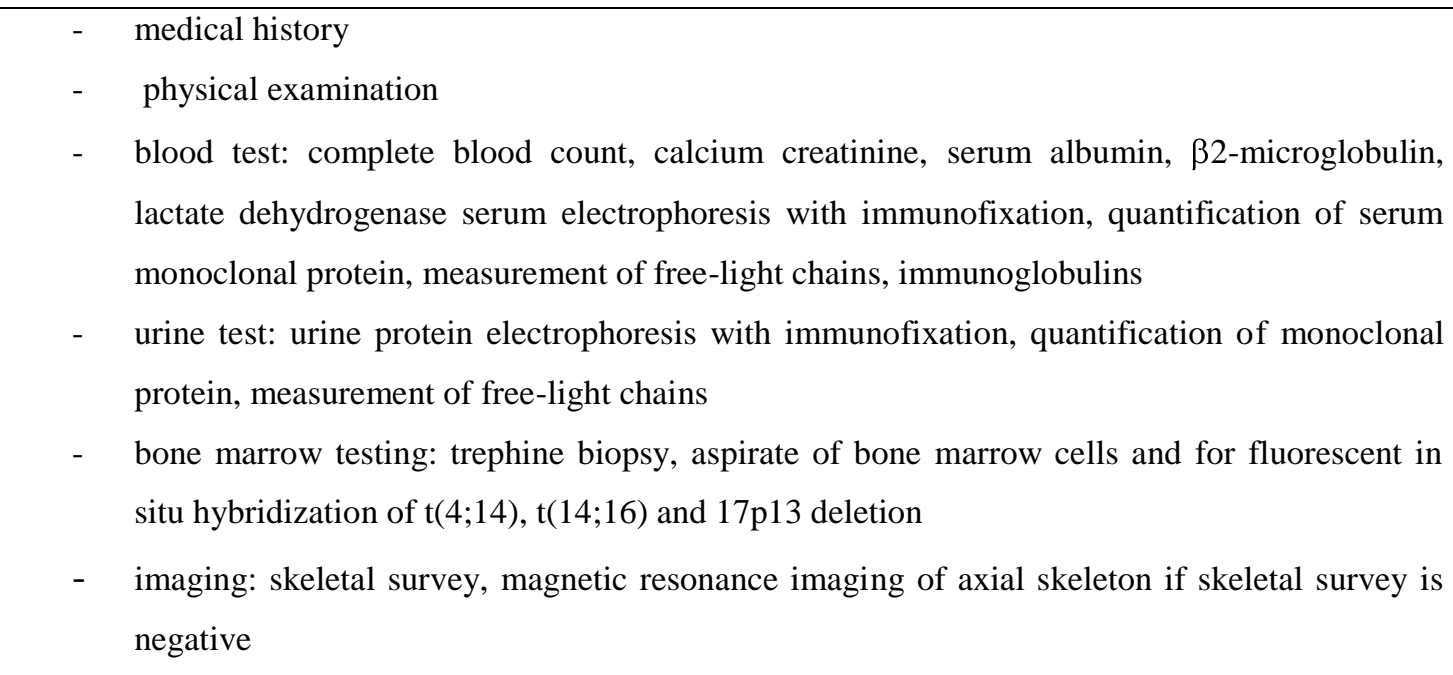 \\
\hline 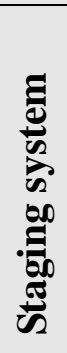 & $\begin{array}{l}\text { International Staging System: } \\
\text { - Stage I: } \quad \text { serum } \beta 2 \text {-microglobulin }<3.5 \mathrm{mg} / 1 \text { and serum albumin } \geq 3.5 \mathrm{~g} / \mathrm{dl} \\
\text { - } \quad \text { Stage II: serum } \beta 2 \text {-microglobulin }<3.5 \mathrm{mg} / 1 \text { and serum albumin }<3.5 \mathrm{~g} / \mathrm{dl} \text { or } \\
\quad \text { serum } \beta 2 \text {-microglobulin } 3.5 \text { to }<5.5 \mathrm{mg} / \mathrm{l} \\
\text { - Stage III: serum } \beta 2 \text {-microglobulin } \geq 5.5 \mathrm{mg} / 1\end{array}$ \\
\hline
\end{tabular}

Table 2. Efficacy of regimens used as a front-line treatment in elderly patients with multiple myeloma

\begin{tabular}{|c|c|c|c|c|c|c|c|}
\hline & & $\mathbf{N}$ & CR & $\geq \mathbf{P R}$ & PFS/EFS/TTP & os & Reference \\
\hline \multicolumn{2}{|c|}{ Thalidomide-based } & & & & & & \\
\hline TD & $\begin{array}{l}\text { T: } 200 \mathrm{mg} \\
\mathrm{D}: 40 \mathrm{mg} \mathrm{d} 1-4,15- \\
18 \text { for a } 28 \text {-day cycle } \\
\text { for } 9 \text { cycles }\end{array}$ & 145 & $2 \%$ & $68 \%$ & $41 \%$ at $24 \mathrm{mo}$ & $\begin{array}{l}61 \% \text { at } 24 \\
\text { mo }\end{array}$ & Ludwig et al ${ }^{15}$ \\
\hline
\end{tabular}




\begin{tabular}{|c|c|c|c|c|c|c|c|}
\hline MPT & $\begin{array}{l}\text { M: } 4 \mathrm{mg} / \mathrm{m} 2 \mathrm{~d} 1-7 \\
\mathrm{P}: 40 \mathrm{mg} / \mathrm{m} 2 \mathrm{~d} 1-7 \\
\text { T: } 100 \mathrm{mg} / \text { day } \\
\text { for six } 4 \text {-week cycles } \\
\text { Maintenance: } \\
\text { T: } 100 \mathrm{mg} / \text { day }\end{array}$ & 129 & $16 \%$ & $76 \%$ & $50 \%$ at $22 \mathrm{mo}$ & $\begin{array}{l}50 \% \text { at } 45 \\
\text { mo }\end{array}$ & Palumbo et al ${ }^{17,18}$ \\
\hline MPT & $\begin{array}{l}\text { M: } 0.25 \mathrm{mg} / \mathrm{Kg} \mathrm{d} 1-4 \\
\mathrm{P}: 2 \mathrm{mg} / \mathrm{kg} \mathrm{d} 1-4 \\
\text { T: } 400 \mathrm{mg} / \mathrm{day} \\
\text { for } 12 \text { 6-week cycles }\end{array}$ & 125 & $13 \%$ & $76 \%$ & $50 \%$ at $28 \mathrm{mo}$ & $\begin{array}{l}50 \% \text { at } 52 \\
\text { mo }\end{array}$ & Facon et al ${ }^{19}$ \\
\hline MPT & $\begin{array}{l}\text { M: } 0.25 \mathrm{mg} / \mathrm{Kg} \mathrm{d} 1-4 \\
\text { P: } 2 \mathrm{mg} / \mathrm{kg} \mathrm{d} 1-4 \\
\text { T: } 100 \mathrm{mg} / \mathrm{day} \\
\text { for } 12 \text { 6-week cycles }\end{array}$ & 113 & $7 \%$ & $62 \%$ & $50 \%$ at $24 \mathrm{mo}$ & $\begin{array}{l}50 \% \text { at } 44 \\
\text { mo }\end{array}$ & Hulin et $\mathrm{al}^{20}$ \\
\hline MPT & $\begin{array}{l}\text { M: } 0.25 \mathrm{mg} / \mathrm{Kg} \mathrm{d} 1-4 \\
\text { P: } 100 \mathrm{mg} \mathrm{d} 1-4 \\
\text { T: } 200-400 \mathrm{mg} / \text { day } \\
\text { for a } 6 \text {-week cycle } \\
\text { until plateau } \\
\text { Maintenance: } \\
\text { T: } 200 \mathrm{mg} / \text { day } \\
\end{array}$ & 182 & $6 \%$ & $42 \%$ & $50 \%$ at $16 \mathrm{mo}$ & $\begin{array}{l}50 \% \text { at } 29 \\
\text { mo }\end{array}$ & Gulbrandsen et al ${ }^{16} \S$ \\
\hline MPT & $\begin{array}{l}\text { M: } 0.25 \mathrm{mg} / \mathrm{Kg} \\
\mathrm{P}: 1 \mathrm{mg} / \mathrm{days} 1-5 \\
\mathrm{~T}: 200 \mathrm{mg} / \mathrm{day} \\
\text { for eight 4-week } \\
\text { cycles } \\
\text { Maintenance: } \\
\text { T: } 50 \mathrm{mg} / \text { day }\end{array}$ & 165 & $66 \%$ & $\begin{array}{l}67 \% \text { at } 24 \\
\text { mo }\end{array}$ & $29 \%$ at $24 \mathrm{mo}$ & $\begin{array}{l}\text { Wijerman } \\
\text { s et al }^{21}\end{array}$ & MPT \\
\hline CTD & $\begin{array}{l}\text { C: } 500 \mathrm{mg} \mathrm{d} 1,8,15 \\
\text { T: } 100-200 \mathrm{mg} / \mathrm{day} \\
\text { D: } 40 \mathrm{mg} \mathrm{d} \mathrm{1-4,12-} \\
15 \\
\text { for a } 3 \text { week cycle }\end{array}$ & 450 & $21 \%$ & $91 \%$ & ND & ND & Morgan et al ${ }^{23}$ \\
\hline \multicolumn{8}{|c|}{ Bortezomib-based } \\
\hline \multicolumn{8}{|l|}{ VMP } \\
\hline \multicolumn{8}{|c|}{$\begin{array}{l}\text { M: } 9 \mathrm{mg} / \mathrm{m} 2 \mathrm{~d} 1-4 \\
\text { P: } 60 \mathrm{mg} / \mathrm{m} 2 \mathrm{~d} 1-4\end{array}$} \\
\hline $\begin{array}{l}\text { V: } 1.3 \mathrm{mg} / \mathrm{m} 2 \\
\text { d } 1,4,8,11, \\
22,25,29,32 \\
\text { for the first } \\
\text { four } 6 \text {-week } \\
\text { cycles; d } 1,8 \text {, } \\
22,29 \text { for the } \\
\text { subsequent } \\
\text { five } 6 \text {-week } \\
\text { cycles }\end{array}$ & 344 & $30 \%$ & $71 \%$ & $\begin{array}{l}50 \% \text { at } 22 \\
\text { mo }\end{array}$ & $70 \%$ at $36 \mathrm{mo}$ & $\underset{25}{\text { ateos et al }}$ & \\
\hline VMP & $\begin{array}{l}\text { M: } 9 \mathrm{mg} / \mathrm{m} 2 \mathrm{~d} 1-4 \\
\text { P: } 60 \mathrm{mg} / \mathrm{m} 2 \mathrm{~d} 1-4 \\
\text { V: } 1.3 \mathrm{mg} / \mathrm{m} 2 \mathrm{~d} 1,8 \\
15,22\end{array}$ & 257 & $24 \%$ & $81 \%$ & $70 \%$ at $36 \mathrm{mo}$ & $\begin{array}{l}87 \% \text { at } 36 \\
\text { mo }\end{array}$ & Palumbo et al ${ }^{27}$ \\
\hline VMP & $\begin{array}{l}\text { M: } 9 \mathrm{mg} / \mathrm{m} 2 \mathrm{~d} 1-4 \\
\text { P: } 60 \mathrm{mg} / \mathrm{m} 2 \mathrm{~d} \mathrm{1-4} \\
\text { V: } 1.3 \mathrm{mg} / \mathrm{m} 2 \text { twice } \\
\text { weekly }(\mathrm{d} 1,4,8,11\end{array}$ & 125 & $22 \%$ & $81 \%$ & $71 \%$ at $24 \mathrm{mo}$ & $\begin{array}{l}81 \% \text { at } 24 \\
\text { mo }\end{array}$ & Mateos et al ${ }^{26}$ \\
\hline
\end{tabular}




\begin{tabular}{|c|c|c|c|c|c|c|c|}
\hline & $\begin{array}{l}22,25,29, \text { and } 32) \\
\text { for one } 6 \text {-week cycle, } \\
\text { followed by once } \\
\text { weekly (d } 1,8,15, \\
\text { and } 22 \text { ) for five } 5- \\
\text { week cycles } \\
\text { Maintenance: } \\
\text { V:1.3 mg/m2 twice } \\
\text { weekly on days } 1,4, \\
8,11, \text { every } 3 \text { months } \\
\text { T: } 50 \mathrm{mg} / \mathrm{d}\end{array}$ & & & & & & \\
\hline \multicolumn{8}{|c|}{$\begin{array}{l}\text { Bortezomib- and Thalidomide- } \\
\text { based }\end{array}$} \\
\hline VTP & $\begin{array}{l}\text { T: } 100 \mathrm{mg} / \text { day } \\
\text { P: } 60 \mathrm{mg} / \mathrm{m} 2 \mathrm{~d} 1-4 \\
\mathrm{~V}: 1.3 \mathrm{mg} / \mathrm{m} 2 \text { twice } \\
\text { weekly }(\mathrm{d} 1,4,8,11 ; \\
22,25,29 \text { and } 32) \text { for } \\
\text { one } 6 \text {-week cycle, } \\
\text { followed by once } \\
\text { weekly (d } 1,8,15 \\
\text { and } 22) \text { for five } 5- \\
\text { week cycles } \\
\text { Maintenance: } \\
\mathrm{V}: 1.3 \mathrm{mg} / \mathrm{m} 2 \text { twice } \\
\text { weekly on days } 1,4, \\
8,11, \text { every } 3 \text { months } \\
\text { P: } 50 \text { mg every other } \\
\text { day }\end{array}$ & 128 & $27 \%$ & $79 \%$ & $61 \%$ at $24 \mathrm{mo}$ & $\begin{array}{l}84 \% \text { at } 24 \\
\text { mo }\end{array}$ & Mateos et al ${ }^{26}$ \\
\hline \multicolumn{8}{|c|}{ Lenalidomide-based } \\
\hline MPR & $\begin{array}{l}\text { M:0.18-0.25 mg/kg d } \\
1-4 \\
\text { P: } 2 \mathrm{mg} / \mathrm{kg} \mathrm{d} \mathrm{1-4} \\
\text { R: } 5-10 \mathrm{mg} \mathrm{d} \mathrm{1-21} \\
\text { for nine 4-week } \\
\text { cycles } \\
\text { Maintenance: } \\
\text { R: } 10 \mathrm{mg} \mathrm{d} 1-21\end{array}$ & 152 & $16 \%$ & $45 \%$ & $55 \%$ at $24 \mathrm{mo}$ & $\begin{array}{l}92 \% \text { at } 12 \\
\text { mo }\end{array} \mid$ & Palumbo et $\mathrm{al}^{33}$ \\
\hline \multicolumn{8}{|l|}{$\mathrm{Rd}$} \\
\hline \multicolumn{8}{|c|}{$\begin{array}{l}\text { R: } 25 \mathrm{mg} \mathrm{d} \mathrm{1-}-21 \\
\text { d: } 40 \mathrm{mg} \mathrm{d} \mathrm{1,8,15,22}\end{array}$} \\
\hline for a 4-week c & ycle 222 & & $4 \%$ & & $68 \%$ & $50 \%$ at 2 & $87 \% \%$ at $24 \mathrm{mo}$ \\
\hline
\end{tabular}


$\mathrm{N}$ indicates number of patients; CR, complete remission; PR partial response; PFS, progression-free survival; EFS, event-free survival; TTP, time to progression; OS, overall survival; M, melphalan; P, prednisone; T, thalidomide;

V, bortezomib; R, lenalidomide; C, cyclophosphamide; D, high-dose dexamethasone; d, low-dose dexamethasone; MPT, melphalan-prednisone-thalidomide; VMP, bortezomib-melphalan-prednisone; VTP, bortezomibthalidomide-prednisone; VMPT, bortezomib-melphalan-prednisone-thalidomide; CTD, cyclophosphamide-thalidomidedexamethasone; MPR, melphalan-prednisone-lenalidomide; NA, not available. $\S$ Updated information was presented at the meeting (American Society of Clinical Oncology, European Haematology Association and American Society of Hematology congress).

Table 3. Safety (grade 3-4 adverse events) of regimens used as front-line treatment in elderly patients with multiple myeloma

\begin{tabular}{|l|l|l|l|l|l|l|l|}
\hline Regimen & N & Neutropenia & Thrombocytopenia & Infection & $\begin{array}{l}\text { Peripheral } \\
\text { neuropathy }\end{array}$ & VTE & Ref \\
\hline
\end{tabular}




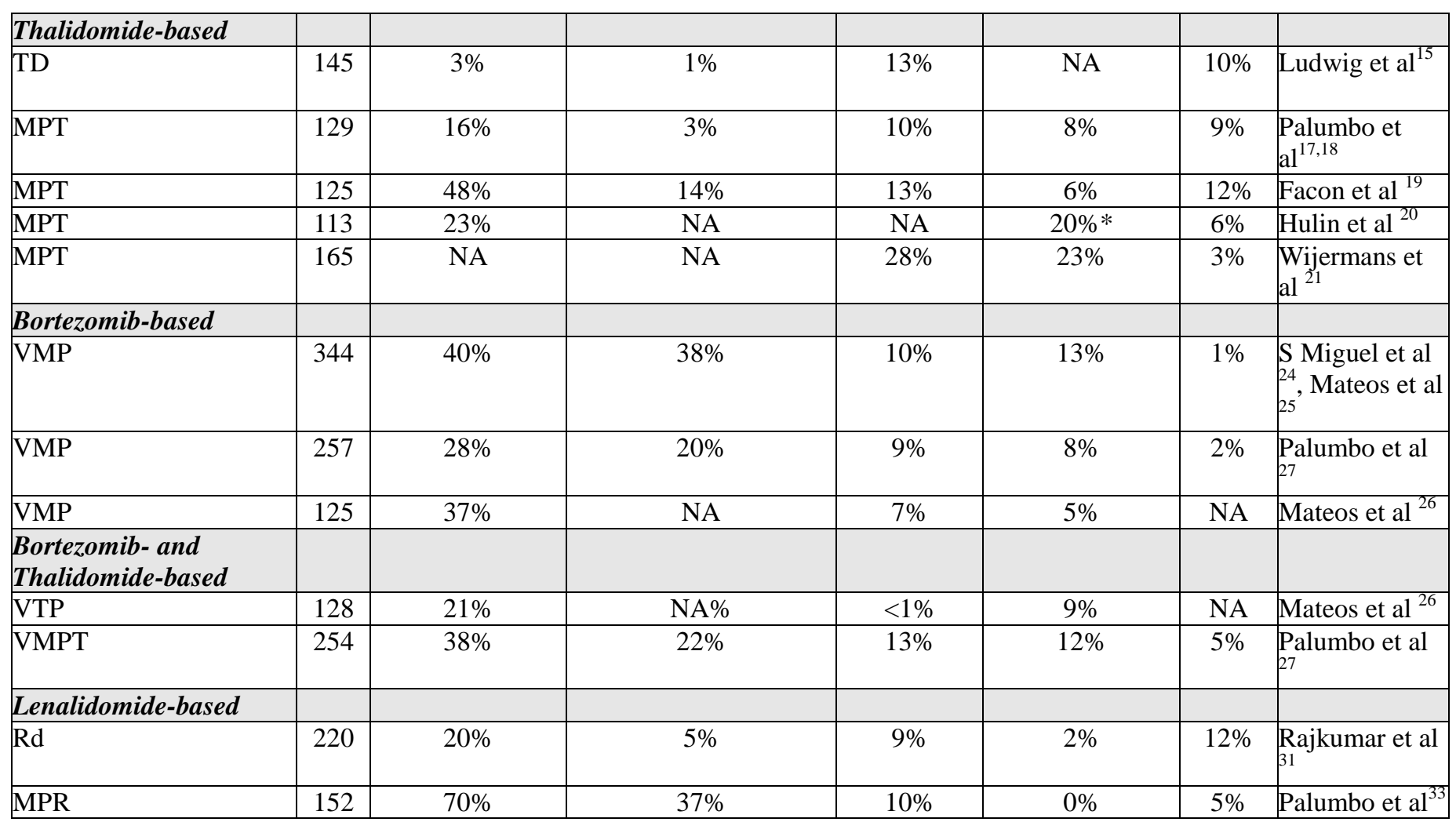

$\mathrm{N}$ indicates number of patients; MPT, melphalan-prednisone-thalidomide; VMP, bortezomib-melphalan-prednisone; VTP, bortezomib-thalidomide-prednisone; VMPT, bortezomib-melphalan-prednisone-thalidomide; CTD, cyclophosphamide-thalidomide-dexamethasone; MPR, melphalan-prednisone-lenalidomide; NA, not available.

*Grade 2-4.

Table 4. Recommended age-adjusted dose reduction

\begin{tabular}{|l|c|c|c|}
\hline & $\mathbf{6 5 - 7 5}$ years & $>75$ years & Further dose reduction \\
\hline Dexamethasone & $40 \mathrm{mg}$ weekly & $20 \mathrm{mg}$ weekly & $10 \mathrm{mg}$ weekly \\
\hline
\end{tabular}




\begin{tabular}{|l|c|c|c|}
\hline Melphalan & $0.25 \mathrm{mg} / \mathrm{kg}$ daily days $1-4$ & $0.18 \mathrm{mg} / \mathrm{kg}$ daily days $1-4$ & $0.13 \mathrm{mg} / \mathrm{kg}$ daily days $1-4$ \\
\hline Thalidomide & $200 \mathrm{mg}$ daily & $100 \mathrm{mg}$ daily & $50 \mathrm{mg}$ daily \\
\hline Lenalidomide (plus dexamethasone) & $25 \mathrm{mg}$ daily days $1-21$ & $15 \mathrm{mg}$ daily days $1-21$ & $10 \mathrm{mg}$ daily days $1-21$ \\
\hline $\begin{array}{l}\text { Lenalidomide (plus melphalan- } \\
\text { prednisone) }\end{array}$ & $10 \mathrm{mg}$ daily days $1-21$ & $5 \mathrm{mg}$ daily days $1-21$ & $5 \mathrm{mg}$ every other day days \\
\hline Bortezomib & $1.3 \mathrm{mg} / \mathrm{m}^{2}$ twice weekly & $1.3 \mathrm{mg} / \mathrm{m}^{2}$ once weekly & $1.0 \mathrm{mg} / \mathrm{m}^{2}$ once weekly \\
\hline
\end{tabular}

